\title{
Mães que cuidam de crianças dependentes de tecnologia em atendimento domiciliar
}

\author{
| ${ }^{1}$ Vanessa Travassos Santos, ${ }^{2}$ Maria Cecilia de Souza Minayo |
}

Resumo: Este artigo tem por objetivo tratar do sofrimento materno no contexto do home care pediátrico. Nele se conta a história de duas mães de crianças que nasceram a termo e tiveram desenvolvimento normal até sofrerem um acidente no domicílio e passarem a necessitar de aparato tecnológico e de equipe de atendimento em casa para sobreviver. É um estudo de natureza qualitativa no qual se desenham duas vinhetas clínicas, para investigar psicanaliticamente a capacidade de resiliência dessas mulheres, e como se dá a (res)significação da dor materna a partir do sentido do cuidado, no contexto de internação domiciliar. Utilizaram-se a Escala de Sobrecarga do Cuidador e a exibição do documentário "Um dia especial" para complementação da análise. O trabalho tem como referencial teórico os estudos da Saúde Coletiva e da Psicanálise nos quais os conceitos de trauma, cuidado e resiliência se destacam. A narrativa das mães vincula as experiências individuais e o contexto social de sua ocorrência. Os resultados demonstraram a importância do home care e a ausência do atendimento psicológico/ psicanalítico, fundamental para ajudar a mãe a encontrar uma interpretação mais positiva de sua situação. Como a pesquisa foi desenvolvida com apenas duas participantes, não se podem generalizar os resultados.

> Palavras-chave: acidente; atendimento domiciliar; cuidador familiar.

\author{
1 Instituto Fernandes Figueira, \\ Fundação Oswaldo Cruz. \\ Rio de Janeiro-RJ, Brasil \\ (vanessatravassos@gmail.com). \\ ORCID: 0000-0001-6645-3609 \\ 2 Escola Nacional de Saúde Pública \\ Sergio Arouca, Fundação Oswaldo \\ Cruz. Rio de Janeiro-RJ, Brasil \\ (maminayo@terra.com.br). \\ ORCID: 0000-0001-6187-9301
}

Recebido em: 25/06/2020 Aprovado em: 15/07/2020 Revisado em: 05/10/2020 


\section{Introdução}

Este estudo busca compreender o sofrimento, as preocupaçóes, a resiliência e as expectativas de mães que cuidam de filhos dependentes de tecnologia para sobreviver. Desde o nascimento, a criança é capaz de gerar grande expectativa para a família, particularmente para sua genitora. O despertar materno (seja ele na própria mãe ou naquele que exerce essa função), aliado ao senso de responsabilidade, é o que possibilita seu desenvolvimento seguro e sadio.

O termo central que define o papel das mães é "cuidado". Etimologicamente, “cuidado" deriva do latim "cogitare”, em português "pensar" (NASCENTES, 1955, p. 145). Portanto, cuidar é pensar em algo, dar atenção, abnegar, concentrar-se, dedicarse, ter consideração e zelo por algo ou alguém. No cuidado subentende-se a paciência, a calma, a mansidão, a bondade e a mansuetude. Boff (1999, p. 12) comenta:

[...] a essência humana não se encontra na inteligência, na liberdade ou na criatividade, mas basicamente no cuidado. [...] No cuidado se encontra o ethos fundamental humano. Quer dizer, no cuidado identificam-se os princípios, valores e as atitudes que fazem da vida um bem-viver e das açóes um reto agir.

Para Boff, ethos significa os princípios que regem, transculturalmente, o comportamento humano para que seja realmente humano no sentido de ser consciente, livre e responsável (BOFF, 1999, p. 195).

A assistência domiciliar consiste na provisão de serviços de atenção à saúde a pessoas doentes, incapacitadas ou crônicas de qualquer idade, em seu domicílio, que, independentemente do hospital, promova tratamento efetivo. O termo home care, de origem inglesa, designa cuidados no lar. A Organização Mundial da Saúde (OMS) define home care como "provisão de serviços de saúde por cuidador formal ou informal no ambiente domiciliar” (WHO, 1999, p. 99). É nesse contexto que se configura a presença do cuidador que, além de responsável pela ajuda cotidiana à pessoa dependente, é referência para trocas de informação com os profissionais da equipe de saúde responsáveis pela assistência domiciliar.

Segundo a Agência Nacional de Vigilância Sanitária (BRASIL, ANVISA, 2006), o conceito de assistência domiciliar, ou home care, apresenta duas áreas de atuação de complexidade diferenciada. A internação domiciliar, quando se fazem necessários equipamentos hospitalares (ex: bomba infusora, suporte ventilatório) como meios de assegurar as funções vitais dos pacientes e a presença ininterrupta de um profissional 
de saúde (em geral de enfermagem, seja técnico ou graduado), para operar os mesmos, além de uma equipe multiprofissional que acompanhe a evolução do paciente.

No atendimento domiciliar, o paciente recebe visitas regulares dos diversos profissionais de saúde, mas não há necessidade do aparato hospitalar nem do acompanhamento por 24 horas. Tanto o atendimento domiciliar quanto a internação domiciliar só são possíveis com a presença de um cuidador. Segundo o Manual Prático do Cuidador (2008), ele é "um ser humano com qualidades especiais, expressas pelo forte traço de amor à humanidade, de solidariedade e de doação”. Existem dois tipos de cuidadores: o formal e o informal. $\mathrm{O}$ formal é aquele que recebe remuneração para exercer a atividade; o informal é a pessoa da família ou da comunidade que a exerce essa atividade sem remuneração.

Os cuidadores familiares pediátricos são alçados a esse posto na maioria dos casos de forma brusca e inesperada. E a maioria são mulheres e, em geral, as mães que, apesar de serem convertidas em cuidadoras de crianças especiais de forma súbita e inusitada, geralmente assumem esse lugar sem nenhum traço de alienação e sentimento de que estejam sendo exploradas. Pelo contrário, observa-se que a atitude das cuidadoras reforça o entendimento de Martin Heidegger (1988) sobre o cuidado (sorge) como o que distingue o humano e constitui a sua essência, cuja construção é constante e ininterrupta. É o mesmo pensamento de Boff (2010) que, apoiado em Heidegger, afirma que o cuidar é estruturante do sujeito e a própria "realização da essência humana" (p. 13). Assim, dentro da estruturação do sujeito, o cuidado aparece como originário, como um a priori (GARELLI, 2015, p. 5) que conforma a humanidade de homens e mulheres.

Este estudo fala de um tipo de cuidado especial - sem fim e sem férias - que, em geral, mães oferecem a seus filhos dependentes de tecnologia, em que sua doação só pode ser de total engajamento. Em geral, a família e, particularmente o cuidador, ao se confrontar com esse tipo de realidade, vive um trauma que exige reconfiguração do cotidiano e das expectativas.

O Escritório de Avaliação de Tecnologia do Congresso Norte-Americano define "dependente de tecnologia" como um pequeno subconjunto da populaçáo deficiente que conta com a tecnologia médica de suporte de vida e normalmente requer complexos cuidados de enfermagem em nível hospitalar (OTA, 1987). Nessa nota técnica, a criança dependente de tecnologia é definida como a que precisa tanto de dispositivo médico para compensar a perda de uma funçâo de seu corpo vital e substancial, 
quanto cuidados para evitar a morte ou agravo de sua deficiência. Ou seja, é a criança que não possui condições clínicas de sobreviver sem o aparato tecnológico.

O quão traumática é a experiência de viver a derrocada de um filho saudável devido a um acidente doméstico? Que tipo de desordem psíquica é colocada a essa mulher? Segundo Laplanche e Pontalis (2001, p. 522), trauma é um "acontecimento da vida que se define pela sua intensidade, pela incapacidade em que se encontra o sujeito de reagir a ele de forma adequada, pelo transtorno e pelos efeitos patogênicos duradouros que provoca na organização psíquica”. Rudge (2009) detalhando Freud, explica que o trauma na psicanálise tem sempre duas acepções. A primeira é "estrutural", ou seja, é o trauma constituinte do sujeito, referido por Otto Rank em The Trauma of Birth (1923) como o nascimento biológico. O segundo sentido é o que Freud denomina "contingente", ou seja, provocado por algo completamente inesperado e desorganizador, tornando o sujeito vulnerável. Um trauma contingente não é antecipado, não é esperado, é sempre fora de propósito, como se mostra neste artigo.

Winnicott (1989) pensou o trauma em crianças como uma ruptura na linha da vida. Para esse autor:

Um trauma é aquilo contra o que um indivíduo não possui defesa organizada, de maneira que um estado de confusão sobrevém seguido talvez por uma reorganização de defesas de um tipo mais primitivo do que as que eram suficientemente boas antes da ocorrência do trauma (WINNICOTT, 1989, p. 259).

A OMS se refere ao acidente que provoca trauma como "um acontecimento fortuito que determina uma lesão reconhecível e constitui, atualmente, importante problema pediátrico e de saúde pública pela sua incidência e repercussōes" (SOUZA; BARROSO, 1999, p. 1). Para o Ministério da Saúde, acidente é "o evento não intencional e evitável, causador de lesôes físicas e ou emocionais" (BRASIL, 2001, p. 427).

Em 2017, a Secretaria de Vigilância em Saúde lançou o caderno Viva: Vigilância de Violências e Acidentes: 2013 e 2014, no qual disponibiliza os altos índices de acidentes domésticos no Brasil. Segundo o caderno:

Não é difícil dimensionar as perdas: o setor saúde tem o gasto de aproximadamente 1,3 bilhão de reais por ano, apenas com internaçóes por causas externas registradas no Sistema de Informaçóes Hospitalares (SIH). A esses valores, somam-se os custos da atenção às urgências, marcadamente em seus componentes de atenção pré-hospitalar e de pronto atendimento hospitalar e não hospitalar. 
Em uma breve pesquisa feita nos DECs - Descritores em Ciências da Saúde na Biblioteca Virtual em Saúde (bvs) - o termo resiliência psicológica está assim descrito: habilidade humana em se adaptar diante de tragédias, traumas, adversidades, privaçôes e de fatores estressantes significativos e corriqueiros da vida. Esse conceito originário da física foi absorvido por outras ciências, como a Psicologia e a Saúde Pública.

O tema é tratado também por filósofos como Prigogine e Stengers (1984) e Atlan (2001), de outra forma, mostrando a capacidade de auto-organização de todo ser vivo e também do ser humano em nível mais complexo quando ele se enfrenta com desafios. Rozemberg et al. (2014, p. 674) ressaltam que a resiliência "envolve processos sociais e intrapsíquicos que estão constantemente se transformando a partir de elementos internos e externos ao sujeito".

A expressão "superação das dificuldades", comumente associada a resiliência, não significa escapar inteiramente ileso de situaçôes estressantes enfrentadas na vida. As adversidades deixam maiores ou menores marcas que, por sua vez, são mais ou menos duradouras, de acordo com a forma específica de cada um em responder às situaçóes de risco às quais está exposto. A marca que é feita na trajetória dessas cuidadoras pode fortalecê-las ou abatê-las conforme as diferenças circunstanciais de vida, as experiências pregressas e os diversos estados emocionais. É importante ressaltar, entretanto, que a resiliência não é um atributo fixo e estável ao longo da vida, mas uma capacidade a ser adquirida e lapidada a cada nova conjuntura.

Aqui são apresentados dois casos extremos de acidentes traumáticos vivenciados por mães cujos filhos sofreram lesões profundas e incapacitantes e passaram a exigir dedicação e cuidado integral. Também são descritas as formas diferentes como cada uma delas reage frente ao sofrimento.

\section{Método}

\section{Sujeitos}

Este é um estudo de caso realizado com duas mulheres cuidadoras, como ilustração das situaçôes vividas cotidianamente pela maioria das que cumprem a mesma função. As duas têm nível superior completo, filhos que nasceram a termo e com desenvolvimento normal, até sofrerem acidente doméstico e se tornarem dependentes de tecnologia para sobreviver. 


\section{Local do estudo}

As histórias dessas duas mulheres foram ouvidas no contexto de um serviço de atendimento domiciliar oferecido às mães do home care do Hospital Prontobaby, no Rio de Janeiro. A empresa surgiu da necessidade de apoiar as máes na continuidade do tratamento hospital. Tanto o hospital quanto o atendimento domiciliar prestam serviços exclusivos em pediatria no município do Rio de Janeiro e adjacências, sendo, até a data desta pesquisa, a única empresa de atendimento domiciliar privada a tratar especificamente de crianças e adolescentes.

\section{Coleta de dados}

Utilizamos, como instrumento para coleta de dados, entrevistas semiestruturadas, o instrumento intitulado Caregiver Burden Scale (CBS) e a exibição do documentário "Um dia especial". As entrevistas ocorreram entre junho/2015 a janeiro/2016 e tiveram em média a duração de 50 minutos, sendo gravadas em áudio e transcritas na íntegra, para posterior análise. As duas cuidadoras aqui apresentadas foram escolhidas porque seus filhos nasceram e se desenvolveram dentro do esperado, mas após um acidente doméstico passaram a necessitar do acompanhamento de um cuidador por 24 horas por dia. A escolha de apenas dois casos permitiu lidar com um tema difícil do ponto de vista existencial, aprofundando tanto suas vivências como suas expectativas para o futuro.

$\mathrm{Na}$ pesquisa, a inspiraçáo veio de outras experiências em que o papel de pesquisadora se aproximou da função de profissional de saúde na interface entre clínica e pesquisa em ciências humanas. Sabemos que nenhuma pesquisa é isenta e que nenhum pesquisador é imparcial, o que nos exigiu estudos, leituras críticas e um distanciamento possível (PAEZ; MOREIRA, 2016). O relato das experiências subsidia a construção da reflexão e da crítica com vistas a explorar a dimensão do sofrimento relacionado ao evento do acidente doméstico. Nesse sentido, as duas máes convidadas a participar da pesquisa aceitaram colaborar de maneira espontânea, sendo-lhes assegurado o anonimato e a certeza de que teriam apoio psicológico caso a rememoração dos fatos lhes suscitasse alguma fragilidade.

$\mathrm{O}$ processo da pesquisa foi dividido em quatro etapas, totalizando quatro encontros com cada mãe. A primeira ocorreu em dois encontros por meio de um roteiro de entrevista semiestruturada, utilizado apenas como orientador, uma 
vez que as duas entrevistadas discorreram livremente sobre sua experiência. Essa etapa gerou duas vinhetas clínicas que permitiram às pesquisadoras ampliar seu olhar e aprofundar cada história de vida, articulando-as com suas experiências profissionais. Finalizada essa etapa, todo o material gravado com o consentimento das entrevistadas, foi transcrito.

$\mathrm{Na}$ segunda etapa, aplicou-se um instrumento intitulado Caregiver Burden Scale (CBS) ou Inventário de Sobrecarga do Cuidador, originalmente desenvolvido em sueco e registrada seu uso pela primeira vez por Elmstahl, Malmberg e Annerstedt (1996). Preliminarmente, foi elaborado para medir impacto em cuidadores de pessoas com doenças crônicas. O CBS foi traduzido para a língua portuguesa, adaptado culturalmente e validado para o Brasil por Medeiros (1998). Esse questionário foi escolhido por nós, por ser considerado adequado para os objetivos do estudo, abrangendo os principais impactos sofridos por um cuidador.

O instrumento é composto por 22 perguntas divididas em cinco grupos, a saber: tensão geral, isolamento, decepção, envolvimento emocional e ambiente. São permitidos ao entrevistado quatro tipos de respostas: de modo algum, raramente, algumas vezes e frequentemente. No primeiro grupo, infere-se o esgotamento a que é submetido um cuidador domiciliar. No segundo, visa-se entender o impacto que esse papel causa na vida social do cuidador. No terceiro, busca-se compreender se existe frustração e descontentamento no desempenho de seu papel. No penúltimo grupo, pretende-se aferir o quanto o cuidador está envolvido com o personagem cuidador. E no quinto e último, analisa-se quanto o entorno pode ajudar ou prejudicar a figura do cuidador.

$\mathrm{Na}$ terceira fase, realizada num único encontro, utilizou-se uma técnica mobilizadora, por meio do documentário "Um dia especial” (2014), que trata das dificuldades enfrentadas no dia a dia por 10 mães de crianças especiais resultante de quadros clínicos diversos, refletindo a multiplicidade das experiências. Por último, realizou-se um estudo retrospectivo dos prontuários, o que trouxe informaçôes precisas em relação a datas e diagnósticos dos dois pacientes.

Este artigo foi construído a partir de uma dissertação de mestrado e todos os componentes éticos da pesquisa foram observados. A pesquisa foi aprovada pelo Comitê de Ética em Pesquisa da Universidade Veiga de Almeida sob o número CAEE 50735415.5.0000.5291. 


\section{Resultados}

Inicia-se esta apresentação mostrando os dados sociodemográficos das duas mães cuidadoras. Chamam atenção a pequena rede de apoio de ambas e o fato de as duas viverem em dedicação integral aos filhos dependentes de tecnologia.

Quadiro 1. Características das duas mães cuidadoras e CDT

\begin{tabular}{|l|l|l|l|}
\hline Características das cuidadoras & Rede de apoio & \multicolumn{1}{|c|}{$\begin{array}{c}\text { Diagnóstico de base da } \\
\text { criança }\end{array}$} & $\begin{array}{l}\text { Tempo de } \\
\text { bome care }\end{array}$ \\
\hline $\begin{array}{l}\text { Leoa, 45 anos. Do lar. Ensino } \\
\text { superior completo. Casada. } \\
\text { Única filha. }\end{array}$ & Marido & $\begin{array}{l}\text { Encefalopatia por traumatismo } \\
\text { craniano e afogamento. }\end{array}$ & 7 anos \\
\hline $\begin{array}{l}\text { Calau, 63 anos. Aposentada. } \\
\text { Ensino superior completo. } \\
\text { Separada. Único filho. }\end{array}$ & Tia & $\begin{array}{l}\text { Encefalopatia por hipoxia } \\
\text { isquêmica, paralisia de todos os } \\
\text { os quatro membros. }\end{array}$ & 10 anos \\
\hline
\end{tabular}

Fonte: as autoras.

Os nomes das duas mulheres são fictícios, atendendo à Resolução n. 196/96 (BRASIL, 2005), para proteger a identidade dos participantes de pesquisas com seres humanos. O codinome foi escolhido como homenagem à dedicação e à abnegação dessas mulheres. "Leoa" ecoa como uma afirmação popular de mulheres fortes que defendem suas causas e seus filhos. "Calau" é um nome genérico atribuído a aves da ordem Bucerotiformes, também conhecidas como bicos-de-corno ou bicos-de-serra.

A análise dos dois casos parte do referencial freudiano de sustentação emocional, a partir do qual é possível entender conceitos como angústia, trauma e culpa, vivenciados por essas mães, no entendimento de que o filho pós-acidente não é mais o filho primevo, sob a luz da psicanálise. A presença sistemática nas residências dessas mulheres permitiu ir além dos objetivos psicoterapêutico-psicanalíticos. Por meio de um material clínico observacional, tornou-se possível compreender as estratégias de ressignificação e de resiliência por meio das quais uma mulher se torna mãe de uma criança especial após o nascimento de um filho saudável.

A seguir descrevem-se os dois casos clínicos a partir do relato livre autobiográfico para a ilustração de processos psicossociais que podem acompanhar a experiência do trauma materno tal como tratado neste texto. 


\section{"Meu Deus a salvará!"}

O ano é 2007. Leoa, 37 anos, natural do Rio de Janeiro, formada em contabilidade. É a filha mais nova, tendo uma irmã quatro anos mais velha que mora com ela. $\mathrm{Na}$ casa residem ainda o cunhado e duas sobrinhas. Leoa namora o rapaz da casa ao lado, nove anos mais novo. Ela tem emprego formal e divide as despesas da casa com a irmá. Ela e o namorado optaram pela permanência em casas separadas, com o intuito de juntar dinheiro para comprar sua própria residência. Em 2005 descobriuse grávida, e em junho de 2006 nasceu sua filha, muito bem recebida e amada por todos. O desenvolvimento da criança transcorreu de forma tranquila, natural, sem intercorrências. Leoa e o namorado, apesar de não oficializarem a união, passaram as alianças para a mão esquerda, tratando-se como marido e mulher.

Ela relata que a irmá se ofereceu para tomar conta da menina quando ela teve que retornar ao trabalho. Em um dia de novembro de 2007, após Leoa retornar do trabalho, percebeu que algo acontecia na vila onde morava, pois todos os vizinhos estavam fora de suas casas. Estranhando o ambiente, Leoa foi direto para casa e ao perguntar por sua filha, a sobrinha mais velha lhe respondeu monossilabicamente que a mãe havia saído com a menina. Leoa descreve que, nesse instante seu telefone tocou, e que, com voz embargada, o marido lhe disse que iria buscá-la. Ao silêncio que se seguiu, Leoa descreve que um misto de medo e desespero passou a tomar conta dela.

A sobrinha acabou por contar que a criança havia caído na piscina da casa e que sua mãe a havia levado para o Hospital Cardoso Fontes, localizado na zona oeste do Rio de Janeiro. Muito nervosa, Leoa dirigiu-se ao hospital. Leoa tomou ciência do acidente. Sua irmã estava ao telefone, no quarto, enquanto a criança, na época com um ano e quatro meses, brincava a seu lado. Estavam na casa a tia, as sobrinhas e uma empregada com problemas auditivos. Ninguém viu o que aconteceu. A menina se sentiu atraída pela área externa e dirigiu-se para a piscina. Conta que havia um obstáculo, um pequeno muro em torno. A criança teve que transpô-lo.

A piscina vazia havia acumulado alguns poucos centímetros de água. Ninguém ouviu os passoas da criança ao sair de casa, e a empregada com problemas auditivos foi quem a encontrou desacordada e gritou por ajuda. Com voz embargada, continua o relato:

Minha filha foi encontrada toda roxa. Disseram-me que fizeram massagem cardíaca, que ela vomitou, que estava toda molinha. As pessoas me contaram que ela estava morta! Se eu perdesse minha filha naquele dia, eu não iria perdoar nunca mais a minha irmá. 
Leoa explica que, no dia seguinte, foi procurada pela médica para iniciar uma bateria de exames na menina e verificar o quanto o cérebro havia sido atingido. A criança estava em coma induzido. Mesmo estabilizada no hospital, não havia neurocirurgião presente. Assim, uma transferência foi solicitada pela médica para o Hospital Prontobaby, localizado na Tijuca e especializado em pediatria. A criança permaneceu internada na UTI por trinta dias, período em que Leoa não saiu de seu lado.

Minha vida parou. Eu entrei com ela no hospital e não sai mais. Só com ela. Tudo, todos os procedimentos, todas as decisóes e escolhas eram comigo.

Durante a internação foram realizados procedimentos como traqueostomia e gastrostomia, uma vez que a menina apresentou dificuldades na respiração e na deglutição. A internação durou seis meses. Ao final desse tempo, uma enfermeira perguntou-lhe se sua filha iria para casa com o home care. Leoa relata que náo sabia o que era um atendimento domiciliar, e acreditava que por uma benção divina sua filha voltaria para casa sem maiores necessidades. Mas no próprio hospital, a instruíram tanto sobre as necessidades da criança quanto das peculiaridades e possibilidades do home care.

A mãe inicialmente contratou o home care somente no horário diurno, o que rapidamente lhe causou exaustão, visto que a criança fazia medicação de uma em uma hora durante a madrugada. Em seguida, modificou o horário para atendimento integral. Ela relata que só depois de criar confiança com a equipe noturna voltou a dormir. Hoje, a criança tem atendimento 24 horas e recebe o apoio de fisioterapia, fonoaudiologia, terapia ocupacional, nutrição, enfermagem e pediatria.

A fala de Leoa ainda é carregada de emoção, decepção, desolamento e frustração em relação aos seus projetos de vida e expectativas. Apesar do isolamento social em virtude da função do tempo integral como cuidadora, vai se tornando mais disponível para as relaçôes e mais confiante na ajuda profissional que recebe no home care. Porém, Leoa não faz planos para o futuro, diz que vive um dia de cada vez. E ressalta que mães que passam por situação semelhante à sua deveriam receber suporte psicológico.

\section{"Essa vida não valeu a pena!"}

O ano é 1990. Calau, 39 anos, natural do Rio de Janeiro, formada em Direito, morando com o companheiro há três anos. Engravida de uma gestação não planejada 
e ao comunicar a notícia ao companheiro, tem como resposta que ela fizesse o que achasse melhor pois ele náo iria se meter. Em junho de 1991 nasceu o menino. Os pais se separaram quando a criança fez um ano.

No início, o pai ainda vinha vê-lo nos aniversários, mas, aos poucos foi se afastando, até não vir mais.

O ano é 2000 e Calau está com 48 anos, morando sozinha com o filho de oito anos. Em um dia de maio, foi visitar seu pai que se encontrava acamado. Calau estava no quarto conversando e fazendo a higiene do idoso, quando o filho saiu do ambiente. Sem saber precisar o tempo decorrido até dar falta dele, a mãe conta que após chamálo sem sucesso, foi ao quintal procurá-lo. Seu pai havia construído na garagem um balanço caseiro, com duas cordas grossas e uma tábua de madeira no meio.

O balanço era bem baixinho, meu pai havia feito quando ele tinha uns três anos. Mas ele tirou a madeira e colocou uma corda apoiando a cabeça, a outra apoiando os pés. Deu impulso - sei que deu impulso, pois seu pé estava machucado - e fez como se fosse voar.

A mãe prossegue dizendo que quando chegou perto do filho, achou que ele estivesse brincando. Mas a criança não se moveu:

Quando cheguei perto, levantei a mão dele, ela caiu. Eu não sei de onde tirei forças para levantá-lo. Ele já pesava 52kg. Eu o suspendi e comecei a gritar: 'Gente, me ajuda!'

Menciona que o vizinho desceu com a chave do carro nas mãos, e foram direto para o Hospital Fátima, em Nova Iguaçu.

Ele chegou lá parado. Fui fazendo respiração boca a boca no caminho. Foi ressuscitado e posto direto no CTI. Mas minha ficha não caía. Voltei para casa, peguei as roupas dele e voltei para buscá-lo.

A recepcionista do hospital tentou trazê-la à realidade, explicando-lhe que a criança encontrava-se no CTI e que não teria alta naquele dia. Foram horas de angústia e de silêncio:

Só me diziam que era grave, era grave, era grave. Naquela época, o hospital não tinha CTI pediátrico. Era só de adulto, e não me deixavam ficar com meu filho. Foi muito difícil.

A lei que estabelece o regime do acompanhamento familiar de crianças, pessoas com deficiência, pessoas em situação de dependência e pessoas com doença incurável em estado avançado e em estado final de vida em hospital ou em unidade de saúde data de setembro de 2009, portanto, nove anos após o acidente. A máe conta que nem recebia informação sobre a gravidade da situação do filho. Numa manhã, ela 
cercou o médico, pedindo-lhe que lhe explicasse. Ele lhe falou da transferência da criança, em função da necessidade de atendimento de neuropediatra. Foi-lhe referido o hospital Prontobaby e ela fez o contato com essa finalidade. Calau contatou o pai do menino, que não o via há quatro anos.

No Hospital Prontobaby, a criança permaneceu por um tempo em coma induzido para diminuição do edema cerebral. A mãe não teve conhecimento sobre o direito ao atendimento domiciliar até que a criança fosse reinternada com pneumonia. Aí, sim, já saiu do hospital com o menino em internação domiciliar.

Eu não sabia direito o que era home care. É uma grande ajuda! Depois do home care ele passou a internar menos e a ficar mais estável.

Atualmente, a criança se encontra em internação domiciliar na modalidade 12 horas (pois não faz nenhuma dieta nem medicação noturna), e tem atendimento de fisioterapia, fonoaudiologia, nutrição, enfermagem e pediatria. Calau mantém a rotina de mãe-cuidadora em sua residência. Como já é aposentada, não tem vontade de praticar nenhuma atividade extra. É importante observar que, apesar de o menino estar com 24 anos de idade atualmente, como sofreu o acidente com oito, o tratamento considera a provável data da encefalopatia para o home care pediátrico. Como Leoa, Calau não faz planos para o futuro. Vive para o cuidado com o filho dependente.

\section{Discussão}

O trauma de ter um filho acidentado domesticamente já é por si só desestruturante. Freud comenta que há duas reaçóes frente a esse perigo. Uma reação afetiva e outra ação protetora. Em "Observaçôes suplementares sobre a angústia" (FREUD, 19251926 [1996], p. 162), o autor enuncia:

A angústia [Angst] tem inegável relação com a expectativa: é angústia por algo. Tem uma qualidade de indefinição e falta de objeto. Em linguagem precisa empregamos a palavra "medo" $[$ Furcht $]$ de preferência a "angústia" [Angst] se tiver encontrado um objeto.

O verdadeiro significado de uma situação de perigo é a posição de desamparo em que o indívíduo é colocado:

Desamparo físico se o perigo for real e desamparo psíquico se for instintual. Ao proceder assim, o indivíduo será orientado pelas experiências reais que tiver tido. (...) Denominemos uma situação de desamparo dessa espécie, que ele realmente tenha experimentado, de situação traumática (FREUD, 1925-1926 [1996], p. 163). 
O desamparo - para a Psicanálise - remete ao "estado do lactente que, dependendo inteirmanete de outrem para a satisfação das suas necessidades (sede, fome), é impotente para realizar a ação específica adequada para por fim a tensão interna" (LAPLANCHE; PONTALIS, 2001, p. 112), isto é, a impressão de impotência e insuficiência, que ficam marcados em nosso insconsciente desde nossos primordios, nos remetem a uma vulnerabilidade extrema de uma angústia não aliviada.

Há um limiar tênue entre o peso do cuidado cotidiano levado a cabo com empenho, e o desequilíbrio, a fragilidade e o desamparo com que são acometidos essas mães cuidadoras. Como mensurar o desamparo sentido por essas mulheres ao verem seus filhos expostos aos perigos de um corpo altamente debilitado e dependente? O pai da psicanálise, em Estudos sobre a histeria (1893-1895), segue elucidando o quanto os traumas podem permanecer no inconsciente durante anos, como representaçôes inconscientes existentes e atuantes, "da mesma forma que um sofrimento psíquico que é recordado no estado consciente de vigilia ainda provoca uma secreção lacrimal muito tempo depois de ter ocorrido o fato" (p. 249-250).

É claro que o sistema do home care que se instala na residência vem trazer um apoio efetivo e eficaz e dar um pouco mais de segurança para as mães, mas ele também exige rearranjos logísticos na residência e novas decisóes do cuidador sobre sua própria rotina social e profissional. Após ter a vida profissional paralisada, mesmo com o apoio do home care, Leoa confidencia sobre seus sentimentos de solidão e de abandono. Uma escuta psicológica poderia proporcionar-lhe elementos para ressignificar a atual rotina, valorizando seu mais nobre ato humano expresso no cuidar (HEIDEGGER, 1988; BOFF, 1999).

Perdi minha mãe há dois anos, a pessoa que me dava força. Perdi a única pessoa que era minha única e verdadeira amiga. Não recebo ajuda de ninguém. Moro de favor na casa da minha sogra, como se fosse uma empregada. Lavo, passo, cozinho, arrumo. Cada um vive sua vida e eu vivo a minha.

A fala de Calau também sugere a necessidade de um acompanhamento psicoterapêutico, no qual a escuta psicólogica permita tamanha dor em relação ao ocorrido com o filho. A quase perda de uma criança não retorna a sua inteira normalidade é uma experiência jamais superada, embora as expectativas tendam a se modificar com o passar dos anos. Calau reforça sua frustração: "tomara que exista outra vida, pois para mim, essa não valeu a pena”. Junto a uma dedicação integral e incondicional, observa-se também que essas duas mães, (quase arquétipos 
de mulheres fortes e indomáveis), além da solidão, do desamparo, da tristeza, sentem responsabilidade pelo ocorrido.

Com relação à análise da escala aplicada, na primeira parte do instrumento CBS, intitulada tensão geral, as duas mães atingiram quase a pontuação máxima, tendo Calau apenas um ponto a mais que Leoa, o que comprova um alto nível de estresse decorrente da posição de cuidador. No segundo tópico intitulado isolamento, ambas também permaneceram perto da pontuação máxima, o que confirma que as duas diminuíram, quando não paralisaram, sua vida social, por conta da internação domiciliar. $\mathrm{Na}$ terceira parte, denominada decepção, ficam explicitados o desolamento e a frustração de ambas as mães em relação aos seus projetos de vida e expectativas, quando respondem, de forma uniforme e equivalente, que esperavam que a vida fosse diferente do que é na idade em que se encontram. Na quarta seção, nomeada envolvimento emocional, ambas as máes cuidadoras atingiram pontuação mínima, o que nos revela que não atribuem culpa sobre o que estão passando as crianças. No último quesito, intitulado ambiente, tanto a primeira quanto a segunda mãe pontuaram e responderam de forma igual, atingindo uma pontuação mediana, mostrando-nos que, apesar de o ambiente não as atrapalhar, existe a preocupação em saber se a criança está sendo cuidada de forma correta.

As pontuações dos dois sujeitos da pesquisa aproximaram-se do nível mais alto, refletindo a realidade de sobrecarga que vivenciam. Ambas as mães entrevistadas vivenciam sozinhas as rotinas dos home care de seus filhos. O instrumento foi respondido sem interrupçōes e, logo após, houve a exibição do filme "Um dia especial" tencionando uma provocação ao debate. Ambas as mães se mostraram bastante mobilizadas após assistir o filme.

Os dois casos estudados acima são advindos de pessoas que têm plano de saúde, e por meio dele, recebem os cuidados de uma empresa de home care. Sem rede de apoio ou recebimento de ajuda pública, não lhes resta alternativa a não ser uma dedicação total para assistir a esse filho, sem possibilidade de escolhas. A essas mães cuidadoras, qualquer tipo de apoio ofertado pelo Estado traria grande alívio e bálsamo a sua angústia e sofrimento no dia a dia.

\section{Consideraçôes finais}

Ao final deste artigo, apresentam-se algumas consideraçóes. A primeira diz respeito à escassez de textos que tratem das máes cuidadoras na perspectiva do 
atendimento domiciliar de crianças e adolescentes dependentes de tecnologia. A invisibilidade das vivências e das situaçóes relacionadas à vida das pessoas com deficiências severas que precisam de atenção no cuidado a saúde em home care torna esse assunto não muito acessível. Isso mostra a importância da produção de conhecimento e de sua aplicação.

O tema aqui tratado não é de domínio público. Felizmente, um número pequeno de pessoas passa por essa situação ou se envolve com ela, não evidenciando relevância epidemiológica. Os profissionais de saúde que atuam junto a esse grupo não podem apenas cumprir sua tarefa técnica. Depois da morte, vivenciar a situação de crianças e adolescentes dependentes de tecnologia ou cuidar deles talvez seja uma das experiências mais dolorosas e sofredoras para as famílias e para qualquer ser humano. É fundamental que as açôes voltadas para a atenção e a promoção da saúde de cuidadores incluam as mães de crianças dependentes de tecnologia, promovendo a compreensão acerca do cuidado do outro e de si, do estabelecimento de estratégias de autoproteção e da resiliência como uma habilidade a ser adquirida e cultivada.

Os dois casos aqui narrados ilustram algumas circusntâncias que envolvem crianças dependentes de tecnologia em contexto de atendimento domiciliar e seus cuidadores. Apesar da situação desorganizadora que os efeitos irreversíveis de um acidente doméstico ou outros problemas graves de saúde causam, o cuidado emerge como essência do ser humano, particularmente de forma predominante nas mães que não abandonam seus filhos. Como lembra Heidegger, o ser humano é (existe) por meio do cuidado. Como sobreviveria uma criança que foi alçada novamente a um desamparo primordial se não fosse o cuidado recebido dessa mãe que abre mão de seu projeto de vida pessoal a favor do bem-estar de seu filho? Trabalho profissional, família, atividades sociais e de lazer geralmente passam a ser postergados ou abandonados. $\mathrm{O}$ cuidado se torna o centro: a preocupação, o pensamento, a atitude e o ato em tempo integral, na maioria dos casos, sem auxílio de terceiros.

A sobrecarga que recai sobre os ombros das mães cuidadoras de crianças cuja saúde depende de tecnologia as leva, frequentemente, a desenvolver estratégias pessoais para lidar com os novos contextos e as novas exigências da vida. Isso aprimora sua capacidade de resiliência e ressignificação, tornando-as seres humanos mais fortes e mais complexos (PRIGOGIINE; STENGERS, 1984; ATLAN, 2001). É muito melhor quando elas recebem o apoio profissional e do afeto familiar. Pois cuidar de uma pessoa doente e que necessita de aparato tecnológico para sobreviver é uma 
tarefa árdua e difícil e requer o desenvolvimento de habilidades físicas, técnicas e emocionais para não se sucumbir ao cansaço e ao estresse. Se a maioria se torna mais resiliente, outra parte cultiva rancor, culpa e depressão, vivendo em sofrimento. É fundamental que as mães cuidadoras tenham ajuda e colaboração profissional, de familiares, de vizinhos, de amigos, criando uma rede social e comunitária de amparo e de suporte (RODRIGUES; SILVA, 2013; MARTINS, 2005). É relevante assinalar que hoje não há uma política pública voltada especialmente ao paciente dependente de tecnologia e a seu cuidador. Programas e políticas públicas precisam existir para essas famílias - sobretudo para as mulheres cuidadoras - para dar-lhes conforto, para prevenir problemas de saúde mental e promover sua resiliência. ${ }^{1}$

\section{Referências}

ATLAN, H. Entre o cristal e a fumaça. Rio de Janeiro, Editora J. Zahar, 2001.

BARLACH, L. O que é resiliência humana? Uma contribuição para a construção do conceito. Dissertação (Mestrado em Psicologia Social) - Instituto de Psicologia, Universidade de São Paulo. Sáo Paulo, 2005. Disponível em: http://www.teses.usp.br/teses/disponiveis/47/47134/ tde-19062006-101545/. Acesso em: 23 jun. 2015.

BRASIL. Ministério da Saúde. Secretaria de Políticas de Saúde. Informes Técnicos Institucionais: Política Nacional de Reduçâo da Morbimortalidade por Acidentes e Violência. Rev. Saúde Pública, v. 34, n. 4, p. 427-30, 2000.

Ministério da Saúde. Agência Nacional de Vigilância Sanitária. RDC no 11 de 2006. Dispóe sobre o regulamento técnico de funcionamento de serviços que prestam atenção domiciliar. Diário Oficial da União, Poder Executivo, Brasília-DF, 2006.

. Ministério da Saúde. Secretaria de Atenção à Saúde Secretaria de Gestão do Trabalho e da Educação na Saúde. Guia Prático do Cuidador. Brasília: Ministério da Saúde, 2008 (Série A. Normas e Manuais Técnicos).

. Ministério da Saúde. Secretaria de Vigilância em Saúde. Departamento de Vigilância de Doenças e Agravos Não Transmissíveis e Promoção da Saúde. Viva: Vigilância de Violências e Acidentes: 2013 e 2014. Brasília: Ministério da Saúde, 2017. 218 p. Disponível em: http:// bvsms.saude.gov.br/bvs/publicacoes/viva_vigilancia_violencia_acidentes_2013_2014.pdf Acesso em: 15 fev. 2017.

BOFF, L. O cuidar e o ser cuidado na prática dos operadores de saúde. Ciência \& Saúde Coletiva, v. 25, n. 2, p. 392-393, 2010.

. Saber cuidar. Ética do humano: compaixão pela terra. Petrópolis: Editora Vozes, 1999. 
ELMSTAHL, S.; MALMBERG, B.; ANNERSTEDT, L. Caregiver's burden of patients 3 years after stroke assessed by a novel caregiver burden scale. Arch. Phys. Med. Rehabil., v. 77, p. 177-182, 1996.

FREUD, S. Estudos sobre a Histeria (1893-1895). In: - Edição standard brasileira das obras psicológicas completas de Sigmund Freud. Rio de Janeiro: Imago, 1996. v. II.

_. Um estudo autobiográfico, inibições, sintomas e ansiedade, análise leiga e outros trabalhos (1926[1925]). In: . Ediçâo standard brasileira das obras psicológicas completas de Sigmund Freud. Rio de Janeiro: Imago, 1996. v. XX.

GARELLI, S. Do instinto de cuidado a uma sociedade cuidadora. A biologia de nossas relaçôes sociais. Magazine D\&D. Italia, 2015. Disponível em: <http://www.biodanza.com.br/ Do\%20instinto\%20de\%20cuidado\%20a\%20uma\%20sociedade\%20cuidadora.pdf $>$. Acesso em: 16 fev 2017.

HEIDEGGER, M. Ser e Tempo. Parte I. Petrópolis: Editora Vozes, 1988.

LAPLANCHE, J.; PONTALIS, J. Vocabulário de psicanálise. São Paulo: Martins Fontes, 2001. MARTINS, R. M. Repositório científico do Instituto Politécnico de Viseu. Revista Millenium, n. 31, maio 2005. Disponível em: http://repositorio.ipv.pt/handle/10400.19/429 Acesso em: 01 mar. 2018.

MEDEIROS, M. M. C. Impacto da doença e qualidade de vida dos cuidadores primários de pacientes com artrite reumatoide: adaptação cultural e validação do Caregiver Burden Scale. 165 f. Tese (Doutorado) - Escola Paulista de Medicina, Universidade Federal de São Paulo, São Paulo, 1998.

NASCENTES, A. Dicionário Etimológico da Língua Portuguesa. Rio de Janeiro, 1955. Disponível em: http://docs16.minhateca.com.br/1012126836,BR,0,0,DICION\%C3\%81RIOETIMOL\% C3\%93GICO-DA-LINGUA-PORTUGUESA.pdf Acesso em: 15 fev. 2018.

PRIGOGINE, I.; STENGERS, I.: Order out of chaos. New York: Bantam Books, 1984.

OFFICE OF TECHNOLOGY ASSESSMENT. Technology-Dependent Children: Hospital vs. Home Care - A Technical Memorandum, OTA-TM-H-38. Washigton, D.C.: U.S. Government Printing Office; 1987. Disponível em: http://www.princeton.edu/ ota/disk2/1987/8728/8728. PDF Acesso em: 11 maio 2015.

RODRIGUES, A. G.; SILVA, A. A. A rede social e os tipos de apoio recebidos por idosos institucionalizados. Rev. Bras. Geriatr. Gerontol., Rio de Janeiro, v. 16, n. 1, p. 159-170, 2013. ROZEMBERG, L. et al. Resiliência, gênero e família na adolescência. Ciênc. saúde coletiva, Rio de Janeiro, v. 19, n. 3, p. 673-684, mar. 2014. Disponível em https://www.scielosp.org/scielo.ph p?pid=S141381232014000300673\&script=sci_abstract\&tlng=es Acesso em: 23 jun. 2017.

RUDGE, A. M. Trauma. Psicanálise passo a passo. Rio de Janeiro: Zahar, 2009. 
SANTOS, V. T. R. O sofrimento materno no contexto de um home care pediátrico: efeitos do acidente doméstico sob um olhar psicanalítico. 130 f. Dissertação (Mestrado em Psicanálise, Saúde e Sociedade) - Universidade Veiga de Almeida, Rio de Janeiro, 2016.

SOUZA, L. J. E. X. de; BARROSO, M. G. T. Revisão bibliográfica sobre acidentes com crianças. Rev.Esc.Enf.USP., v. 33, n. 2, p. 107-12, jun. 1999.

UM dia especial. Direção de Yuri Amorim. Rio de Janeiro: Jica/VPAAPS-FaPERJ, 2013. 1 DVD (80 min).

WINNICOTT, D. W. The concept of trauma in relation to the development of the individual within the Family. In: . Psychoanalitic Explorations. London. Karnac, 1989.

WORLD HEALTH ORGANIZATION. Home Care issues and evidence. Home-based and long-term care. Geneva: WHO, 1999. Disponível em: http://www.apps.who.int/irid/ handle/10665/66096. Acesso em: 2 out. 2013.

\section{Nota}

${ }^{1}$ V. T Santos realizou o trabalho de campo e foi responsável pela concepção, discussão teórica e metodológica, análise e redação artigo. M. C. Minayo participou da concepção, discussão teórica e metodológica e análise constantes do artigo. 


\section{Abstract}

\section{Mothers who care for technology-dependent children in home care}

This article aims to address maternal suffering in the context of pediatric home care. It tells the story of two mothers of children who were born at term and had normal development until they suffered an accident at home and started to need technological equipment and a home care team to survive. It is a qualitative study in which two clinical vignettes are designed, to psychoanalytically investigate the resilience of these women, and how the (re)framing of maternal pain occurs from the sense of care, in the context of home care. The Caregiver Overload Scale and the exhibition of the documentary "Um dia especial" were used to complement the analysis. The work has as a theoretical reference the studies of Collective Health and Psychoanalysis in which the concepts of trauma, care and resilience stand out. The mothers' narrative links the individual experiences and the social context of their occurrence. The results attested the importance of home care and the absence of psychological / psychoanalytic care, essential to help the mother to find a more positive interpretation of her situation. As the research was developed with only two participants, the results cannot be generalized.

Keywords: accident; home care; family caregiver. 